\title{
Benefits of CPFR and VMI Collaboration Strategies: a Simulation Study
}

\author{
Raj Kamalapur \\ University of Wisconsin Oshkosh \\ kamalapd@uwosh.edu \\ David Lyth \\ Western Michigan University \\ david.lyth@wmich.edu \\ Azim Houshyar \\ Western Michigan University \\ azim.houshyar@wmich.edu
}

\begin{abstract}
This study provides managerial insight to pursue Collaborative Planning Forecasting and Replenishment (CPFR) or Vendor Managed Inventory (VMI) strategy for both the retailer and manufacturer under different supply chain settings. Discrete event simulation is used to investigate the cost benefits of CPFR and VMI strategies over Traditional Supply Chain (TSC) in a variable demand environment. The conceptual model is a two-echelon production-inventory system with a manufacturer and a retailer. The results from this study suggest that when compared to TSC, both VMI and CPFR achieve cost benefits in inventory management for both the manufacturer and retailer. Under most supply chain settings, higher cost benefits are achieved in CPFR compared to VMI. Also, CPFR achieves higher cost benefits when demand variability is high, production capacity is low, backorder penalty cost is high and delivery lead time is long. However, when production capacity is high and delivery lead time is short, the cost benefits of CPFR and VMI are significantly lower.
\end{abstract}

Key Words: CPFR, VMI, Collaboration Strategy, Simulation Modeling, Inventory Management 


\section{INTRODUCTION}

To manage demand variability in supply chain, many manufacturers, distributors and retailers maintain high level of safety stock inventory which increases overall cost of inventory management. For example, in 1996, approximately $\$ 700$ billion or almost $30 \%$ of the $\$ 2.3$ trillion in retail supply chain was in safety stock inventory (Lewis, 1998). The recent Annual State of Logistics Report, reports that over $\$ 1$ trillion is spent annually on logistics, with 33 percent being attributed to inventory holding cost (Wilson, 2006). In recent years, many academic researchers and practitioners have emphasized that information sharing between supply chain members can significantly reduce inventory levels and improve service levels in the supply chain. Many research studies have shown the benefits of demand information sharing between a retailer and manufacturer (Gavirneni et al., 1999; Lee et al., 2000; Zhao et al., 2002). Most of these studies also show that the manufacturer gains more benefits of information sharing compared to the retailer. In this situation, the retailer has little incentive to share information with the manufacturer. In order to encourage retailers to share information, different collaboration strategies have been developed and implemented in many industries with mixed results (Cooke, 1998; Baljko, 2003; Simchi-Levi et al., 2003; Seifert, 2003). Among them, Vendor Managed Inventory (VMI) and Collaborative Planning, Forecasting and Replenishment (CPFR) are most popular, which are considered in this study. Generally, collaboration strategies such as CPFR and VMI require different types of information sharing which can impact the cost benefits of these collaboration strategies. Using simulation methodology, this study aims to investigate and compare the cost benefits of CPFR and VMI over TSC for both the manufacturer and the retailer.

This paper is organized in the following order: Section 1 provides a brief introduction to TSC, VMI and CPFR collaboration strategies. Section 2 provides a brief literature review, problem statement and the research questions. Section 3 describes the conceptual model, research methodology, the control variables and response variables used for this study. Section 4 provides results and discussion along with control variables which have a significant impact on VMI and CPFR collaboration strategies. Finally, Section 5 provides the conclusions and recommendations for future research.

\subsection{Traditional Supply Chain (TSC)}

In a Traditional Supply Chain (TSC), with a supplier (e.g. manufacturer) and a customer (e.g. retailer), no information is shared, and only orders are placed by the customer. The customer is responsible to track their inventory levels and create a purchase order to make appropriate inventory replenishment decisions (e.g. order quantity and/or order timing). The supplier has no information about future demand or inventory levels at their customer's locations and so has no prior knowledge about the quantity and/or time of the purchase order from their customer. In this situation, the supplier maintains a higher level of safety stock inventory to meet their customer orders. Additionally, the customer may also maintain a higher level of safety stock inventory, especially when production capacity is limited. However, this decentralized decision-making leads to demand distortion, also known as bullwhip effect. Demand distortion impacts supply chain members with inaccurate forecasts, inefficient production planning, increased transportation costs, and increased overall cost of inventory management (Lee et al. 1997). Many authors have suggested that information sharing among supply chain members helps to reduce demand distortion, which in turn helps reduce cost of inventory management in the supply chain (Gavirneni et al., 1999; Lee et al., 2000).

\subsection{Vendor Managed Inventory (VMI)}

Vendor Managed Inventory (VMI) is a collaboration strategy where sales and inventory level information are usually shared by the customer with the supplier. In a typical VMI agreement, the supplier is given the authority and responsibility to make inventory replenishment decisions for their customer. Generally, the customer is not involved in decision making activities, but is responsible for sharing accurate and timely sales and inventory level information with the supplier. One of the earliest VMI agreements was pioneered by Wal-Mart (retailer) with Procter \& Gamble (manufacturer) in the late 1980s (Cooke 1998). This agreement, originally known as Continuous Replenishment Program (CRP), gave Procter \& Gamble the authority and responsibility to make appropriate inventory replenishment decisions for Wal-Mart. Based on the agreement, WalMart shared sales and inventory level information on a regular basis, and Procter \& Gamble used this information to make efficient inventory replenishment decisions for Wal-Mart. 
This agreement between Wal-Mart and Procter \& Gamble helped improve service levels and reduce inventory management costs for both the supply chain partners. With the success of this VMI agreement, several companies in many different industries implemented VMI partnerships with mixed results (Lapide, 2001; Baljko, 2003; Simchi-Levi et al., 2003). It is important to understand the reasons behind why some VMI implementations were successful, while others did not achieve the needed benefits. It is well understood that in a typical VMI agreement, the customer rarely shares sales forecast or future demand requirements and usually is not involved in decision making activities such as demand forecasting, replenishment planning, etc. So the supplier only gains partial visibility of their customers' demand which can impact production planning and cost of inventory management. However in a variable demand environment with production capacity constraints, the availability of future demand requirements can be critical for both supply chain partners. So to gain full demand visibility, it is important for the customer to share demand forecast and also be involved in decision making activities. To remedy this shortcoming of VMI, a newer form of collaboration strategy known as CPFR was developed.

\subsection{Collaborative Planning, Forecasting and Re- plenishment (CPFR)}

CPFR is considered to be the latest strategy in the evolution of supply chain collaboration. Some of the earlier collaboration strategies like CRP and VMI focused on inventory replenishment activities and did not consider the importance of demand forecasting and production planning activities. However, CPFR is a comprehensive collaboration strategy that provides an excellent opportunity for both the customer and the supplier to be involved in demand forecasting and inventory replenishment planning activities.

CPFR also originated from a partnership between two companies and Wal-Mart can be credited in initiating the development of CPFR. In 1995, the first CPFR project, originally known as Collaborative Forecasting and Replenishment (CFAR) was initiated by Wal-Mart (retailer) with Warner-Lambert (manufacturer). Consulting company Benchmarking Partners and the software companies SAP and Manugistics supported them in this project (Seifert, 2003). Listerine mouthwash products were used to test this collaboration strategy during the pilot project. Wal-Mart and Warner-Lambert indepen- dently developed their demand forecasts and compared them on a weekly basis. Any discrepancies between their forecasts were resolved which helped both companies to work with a single forecast. Additionally, both companies together made decisions on inventory replenishment activities. This initial project was considered a success and since then several companies have been involved in implementing CPFR with their suppliers and/or their customers (Seifert, 2003; Esper \& Williams, 2003).

\section{LITERATURE REVIEW}

As information sharing is the foundation for any collaboration strategies, the decisions on the level of collaboration are strongly correlated with decisions on the type of information shared between the supply chain partners. In a supplier-customer (e.g., manufacturer-retailer) supply chain setting, there are many analytical and simulation studies that compare the benefits of demand information sharing with no information sharing in a traditional supply chain (Bourland et al., 1996; Gavirneni et al., 1999; Lee et al. 2000; Chen et al., 2000; Xu et al., 2001; Zhao et al., 2002; Lau et al. 2004). Most of these studies show that demand information sharing helps to reduce cost of inventory management in the supply chain. However, there are very few analytical or simulation studies that compare the benefits of VMI and CPFR over the traditional supply chain (TSC). For example; Boone et al., (2002), Disney et al., (2004), Cigolini \& Rossi, (2006) and Sari (2008) are some studies that consider this situation. Boone et al., (2002) consider a four-level supply chain and use simulation modeling to show the benefits of CPFR compared to reorder point (ROP) method on the customer service level. Disney et al., (2004) use a four-level supply chain and utilize the beer game to determine the bullwhip effect of various supply chain strategies like VMI, EPOS (Electronic Point of Sales) over the traditional supply chain. Cigolini \& Rossi, (2006) consider a four level supply chain and use simulation modeling to compare benefits of CPFR and VMI over LCA (Loosely Collaborative Approach) on service level and forecasting accuracy. Similarly, Sari, (2008) consider a four-level supply chain using simulation modeling to compare the benefits of CPFR and VMI over TSC on service level and total supply chain cost. Setamanit (2009) evaluate the effect of VMI in a four-echelon supply chain using simulation modeling. The study compares the traditional supply chain (TSC) with three different VMI supply chain structure. The study concludes that VMI helps to reduce the total cost of the supply chain in all three 
VMI supply chain structures when compared to traditional supply chain (TSC). Hall and Saygin (2011) study the effect of information sharing in a four-echelon supply chain using simulation modeling. They consider three experimental factors namely; capacity tightness, delivery reliability and information sharing modes to determine the impact on the total cost in the supply chain. The three information sharing modes are inventory information sharing (INV), demand information sharing (CD) and reliability information (RI) sharing. The study concludes that all three information sharing modes help in reducing the cost in the supply chain.

The studies comparing the benefits of collaboration strategies like VMI and CPFR over TSC mostly consider a multi-echelon supply chain and focus on service level and/or cost savings achieved by the entire supply chain. These studies do provide valuable information to pursue the appropriate collaboration strategy based on a multi-echelon supply chain setting. However, most collaboration strategies typically involve two trading partners (e.g. manufacturer and retailer) and the decision to pursue appropriate collaboration strategy is based on individual benefits gained by each supply chain partner under different supply chain settings. Based on the literature review and to the best of our knowledge, there are no studies that compare the benefits of CPFR and VMI over TSC in a two-echelon supply chain consisting of a manufacturer and a retailer in a variable demand environment.

Since information is shared in VMI and CPFR collaboration strategies, it is expected that both CPFR and VMI will perform better than TSC in reducing inventory management cost for the manufacturer and the retailer. CPFR is generally considered a more advanced collaboration strategy and is expected to achieve higher benefits. However, the implementation and operational cost of CPFR can generally be higher for the supply chain partners. So the main motivation for this study is to investigate the cost benefits of CPFR and VMI compared to TSC for both the manufacturer and retailer under different supply chain settings. The following two research questions are investigated for this research study.

In a variable demand environment, does CPFR perform better than VMI and TSC to help reduce the cost of inventory management for both the manufacturer and the retailer?

In a variable demand environment, how do factors like production capacity, backorder penalty cost and delivery lead time impact the choice of CPFR or VMI for the manufacturer and retailer?

\section{RESEARCH METHODOLOGY}

This study uses discrete event simulation (Arena software from Rockwell Automation) to develop three different simulation models (TSC, VMI, CPFR) to determine their impact on inventory management cost for both retailer and manufacturer. Simulation is typically used when analytical model cannot accurately describe the time varying behavior and stochastic nature of the supply chain. According to Law and Kelton (2000), many real world systems with stochastic elements cannot be described accurately using an analytical model. The dynamic nature of supply chains in a variable demand environment makes it necessary to use simulation methods for studying the time varying behavior of supply chain systems. Additionally, simulation helps to capture the interactions between the manufacturer's decisions and the retailer's decisions in a variable demand environment.

\subsection{Simulation Modelling}

This section describes conceptual model used to develop the simulation models. The conceptual model is a two-echelon production-inventory system with a make-to-stock manufacturer (plant and warehouse) and a retailer. The information shared and decisions made in the three supply chain strategies are shown in Figure 1, Figure 2 and Figure 3. All decisions by the retailer and manufacturer are made beginning of each period, where review period is one week. Demand forecast for both the retailer and the manufacturer is developed using exponential smoothing forecast technique. The smoothing factor for the retailer and the manufacturer is selected based on minimizing forecast error at their locations. Periodic review order-up-to inventory policy $(R, S)$ is used to determine the order quantity for retailer and production quantity for the manufacturer during each period. The order quantity and the production quantity during each period is the difference between order-up-to level and current inventory position at their respective locations. The safety stock for both the retailer and manufacturer is calculated using service level, standard deviation of forecast error and the lead time. The service level is determined based on inventory holding cost and the backorder penalty cost to minimize the inventory management costs. 


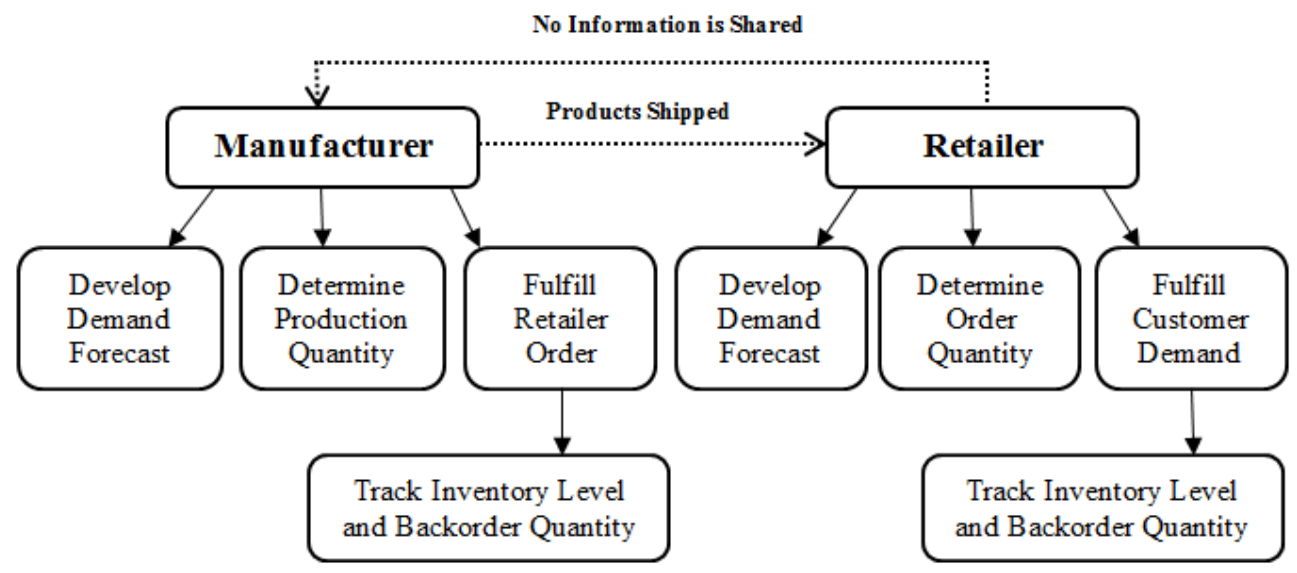

Figure 1 - Information Shared and Decisions made in Traditional Supply Chain

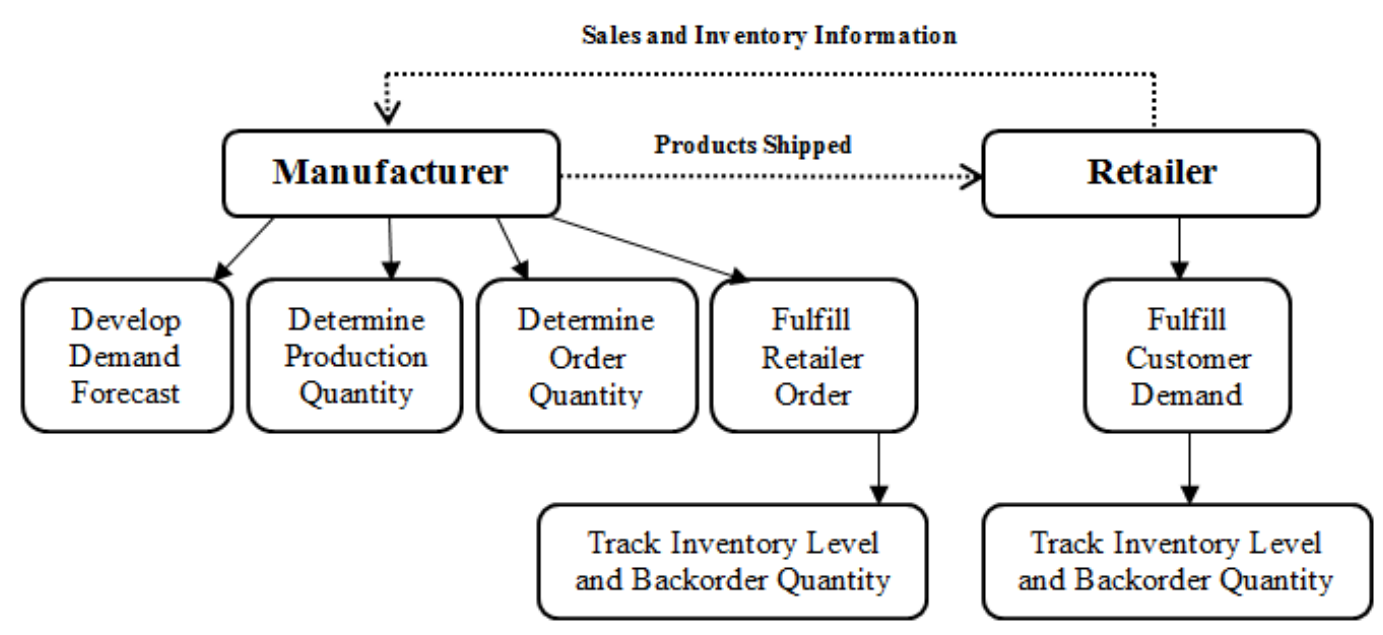

Figure 2 - Information Shared and Decisions made in VMI Supply Chain

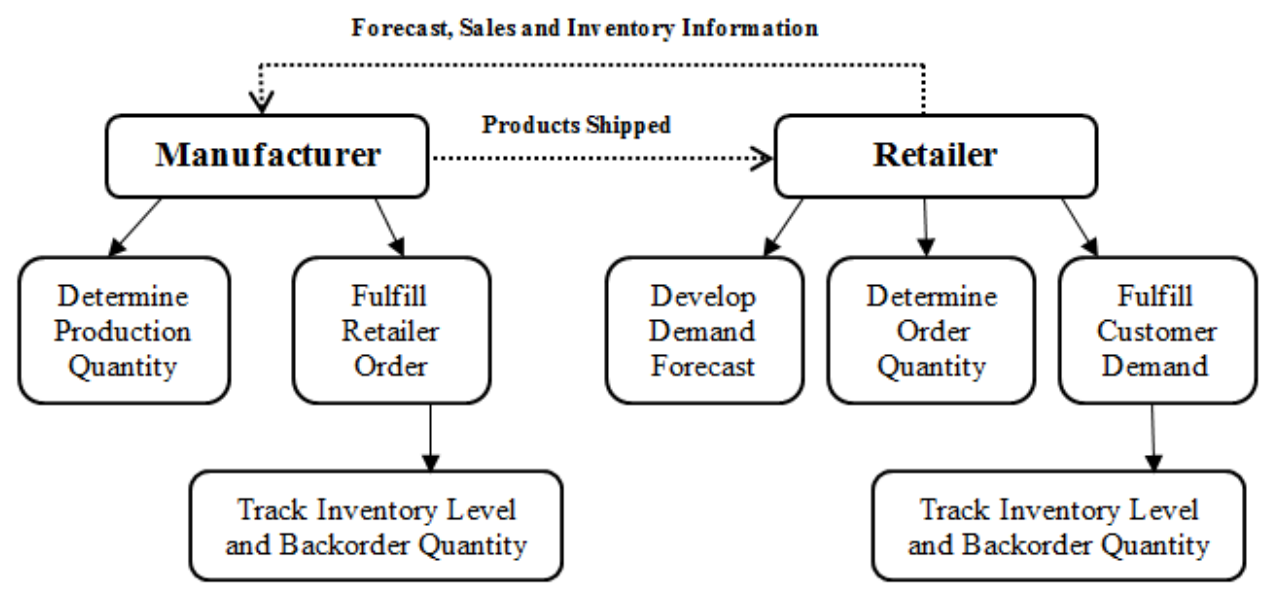

Figure 3 - Information Shared and Decisions made in CPFR Supply Chain 
Customer demand for retailer during each period is generated in the three simulation models. Customer demand, demand forecast, order-up to inventory level, order quantity and production quantity are updated during each period of the simulation run. Customer demand, order quantity and production quantity are non-negative. Manufacturer uses lot-for-lot production strategy and has production capacity constraints. Production lead time is one period and transportation lead time from plant to warehouse is assumed to be negligible. Both the retailer and manufacturer fulfill their demands from their available inventory and any demand not met is backordered with a backorder penalty cost to be fulfilled during the next period.

\subsection{Sequence of Events in Traditional Supply Chain}

The retailer and manufacturer use traditional supply chain (TSC) before any collaboration agreement is reached between them. As shown in Figure 1, only orders are placed by retailer and no other information is shared with manufacturer. In this situation, the retailer and manufacturer make inventory replenishment decisions independently, with the manufacturer in a less favorable position regarding demand information. The sequence of events is as follows. Beginning of each period, the retailer receives shipments (if any) from manufacturer, and customer demand (plus any backorder) is fulfilled from the available inventory. Similarly, the manufacturer's warehouse receives shipments from the plant, and retailer order (plus any backorder) is fulfilled from the available inventory. Any unfulfilled demand for both the retailer and the manufacturer is backordered with a backorder penalty cost. Next, both the retailer and the manufacturer forecast their lead time demand, calculate their order up-to inventory level and determine order quantity (by retailer) and production quantity (by manufacturer) to bring inventory to their order up-to level. These actions are taken by the retailer and manufacturer simultaneously during each period. The manufacturer uses lot-for-lot production strategy, and if production quantity needed is more than available production capacity, only the maximum available quantity is produced. Finally, the retailer cost and the manufacturer cost per period are calculated based on inventory level or backorder quantity at their respective locations at the end of each period.

\subsection{Sequence of Events in VMI Supply Chain}

In VMI supply chain, the retailer shares sales and inventory level information with manufacturer during each period. The retailer is not involved in any decision making and the manufacturer takes responsibility to make inventory replenishment decisions for retailer. The sequence of events is as follows. Beginning of each period, the retailer receives shipments (if any) from manufacturer, and the customer demand (plus any backorder) is fulfilled from available inventory. Similarly, manufacturer's warehouse receives shipments from the plant and the retailer order (plus any backorder) is fulfilled from the available inventory. Any unfulfilled demand for the retailer and the manufacturer is backordered with a backorder penalty cost. Next, manufacturer develop their demand forecast using retailers sales information, calculate retailers order up-to inventory level and determine retailer's order quantity based on the inventory level at retailer location. Manufacturer follows an echelonbased inventory policy in their production planning and inventory replenishment decisions. Under echelon-based inventory policy, the manufacturer considers their own inventory level plus inventory level of retailer, any backorder quantity and inventory in transit to determine their production quantity (Axsater and Rosling, 1993). Manufacturer uses lot-forlot production strategy, and if production quantity needed is more than available production capacity, only the maximum available quantity is produced. Finally, the retailer cost and the manufacturer cost per period are calculated based on inventory level or backorder quantity at their respective locations at the end of each period.

\subsection{Sequence of Events in CPFR Supply Chain}

In CPFR supply chain, the retailer shares forecast, sales and inventory level information with the manufacturer during each period. In this situation, the manufacturer does not forecast and uses the forecast information shared by the retailer. The sequence of events is as follows. Beginning of each period, the retailer receives shipments (if any) from manufacturer and customer demand (plus any backorder) is fulfilled from the available inventory. Similarly, the manufacturer's warehouse receives shipments from the plant and the retailer order (plus any backorder) is fulfilled from available inventory. Any unfulfilled demand for the retailer and manufacturer is backordered with a backorder penalty cost. Next, the retailer develops demand forecast from actual customer demand, and both the retailer and manufacturer calculate their order up-to inventory level and de- 
Raj Kamalapur, R., Lyth, D., Houshyar, A.: Benefits of Cpfr and Vmi Collaboration Strategies: a Simulation Study

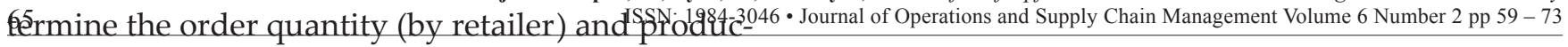
tion quantity (by manufacturer) to bring inventory to their order up-to level. Manufacturer follows an echelon-based inventory policy in their production planning and inventory replenishment decisions. Under echelon based inventory policy, the manufacturer considers their own inventory level plus inventory level of retailer, any backorder quantity and inventory in transit to determine their production quantity (Axsater and Rosling, 1993). Manufacturer uses lot-for-lot production strategy, and if production quantity needed is more than available production capacity, only the maximum available quantity is produced. Finally, the retailer cost and the manufacturer cost per period are calculated based on inventory level or backorder quantity at their respective locations at the end of each period.

\subsection{Experimental Design}

The purpose of an experimental design is to develop a methodology to track the changes in performance measures by varying factors under study during experimental runs. According to Law and Kelton (2000), "One of the principal goals of experimental design is to estimate how changes in input factors affect the results or responses of the experiment." The main motivation for this research is to investigate the benefits of collaboration strategies like VMI and CPFR over TSC in a variable demand environment. In this study, independent variables (control variables) are changed to study impact on depen-

dent variables (response variables) in the three different supply chain strategies (TSC, VMI and CPFR).

Five control variables with three levels each are considered for this study as shown in Table 1. Demand variability can play an important role in determining the type of collaboration strategy to pursue in a supply chain. Similarly, most manufacturers have production capacity constraints, and also backorder penalty cost and delivery lead time are environmental factors that can have a significant impact on the cost of inventory management for both the retailer and the manufacturer.

Different types of demand patterns have been used in information sharing and supply chain collaboration studies. Many studies in information sharing have used auto-correlated demand type. Lee et al. (2000) examined weekly sales data of 150 products at a major supermarket in United States over a two year period and found that sales pattern is significantly auto-correlated. This study considers autocorrelated demand type with three different levels of variable demand. Auto-correlated demand is generated using, $D_{t}=d+Q_{t-1}+\varepsilon_{t^{\prime}}$ where, $d=$ initial mean, $\varrho=$ correlation factor and $\varepsilon_{\mathrm{t}}=$ i.i.d. normally distributed with mean zero and standard deviation $\sigma$. The correlation factor of 0.5 is considered and three levels of variable demand are generated by varying $\sigma$ in the above equation.

Table 1 - Control Variables Considered for this Research

\begin{tabular}{|c|c|c|}
\hline Control Variables & Details for Control Variables & Other Details \\
\hline $\begin{array}{c}\text { Supply Chain Strategy } \\
\text { (SCS) }\end{array}$ & $\begin{array}{c}\text { Traditional Supply Chain (TSC) } \\
\text { Vendor Managed Inventory (VMI) } \\
\text { Collaborative Planning, Forecasting } \\
\text { and Replenishment (CPFR) }\end{array}$ & $\begin{array}{c}\text { CPFR and VMI are com- } \\
\text { pared with TSC }\end{array}$ \\
\hline $\begin{array}{c}\text { Variable Demand } \\
\text { (VDR) }\end{array}$ & $\begin{array}{c}\text { Low Demand Variability, } \sigma=10 \\
\text { Med Demand Variability, } \sigma=20 \\
\text { High Demand Variability, } \sigma=30\end{array}$ & $\begin{array}{c}\text { Average Demand is } \\
100 \text { units per period }\end{array}$ \\
\hline $\begin{array}{c}\text { Production Capacity } \\
\text { (PCM) }\end{array}$ & $\begin{array}{c}\text { Low Production Capacity, 1.20 } \\
\text { Med Production Capacity, } 1.35 \\
\text { High Production Capacity, } 1.50\end{array}$ & $\begin{array}{c}\text { Production Capacity is } \\
\text { factor of Avg. Demand }\end{array}$ \\
\hline $\begin{array}{c}\text { Backorder Penalty } \\
\text { (BOP) }\end{array}$ & $\begin{array}{c}\text { Low Backorder Penalty Cost, } 9 \\
\text { Med Backorder Penalty Cost, 19 } \\
\text { High Backorder Penalty Cost, 32 }\end{array}$ & $\begin{array}{c}\text { Backorder Penalty is } \\
\text { factor of Holding Cost }\end{array}$ \\
\hline $\begin{array}{c}\text { Delivery Lead Time } \\
\text { (DLT) }\end{array}$ & $\begin{array}{c}\text { Low Delivery Lead Time, } 1.0 \\
\text { Med Delivery Lead Time, } 2.0 \\
\text { High Delivery Lead Time, 3.0 }\end{array}$ & $\begin{array}{c}\text { Delivery Lead Time is } \\
\text { factor of Review Period }\end{array}$ \\
\hline
\end{tabular}


Table 2 - Response Variables Considered for this Research

\begin{tabular}{|c|c|}
\hline Response Variables & Other Details \\
\hline $\begin{array}{c}\text { Retailer Cost } \\
\text { (per period) }\end{array}$ & $\begin{array}{c}\text { Inventory Holding Cost and Backorder Penalty } \\
\text { Cost for the Retailer at end of each period }\end{array}$ \\
\hline $\begin{array}{c}\text { Manufacturer Cost } \\
\text { (per period) }\end{array}$ & $\begin{array}{c}\text { Inventory Holding Cost and Backorder Penalty } \\
\text { Cost for Manufacturer at end of each period }\end{array}$ \\
\hline
\end{tabular}

The retailer cost per period and manufacturer cost per period are used as performance measures (response variables) as shown in Table 2. The retailer cost and manufacturer cost are calculated at the end of each period, based on the available inventory or backorder quantity at the retailer and manufacturer locations. The inventory holding cost per period for the retailer and the manufacturer is assumed to be $\$ 1.5$ and $\$ 1.0$ respectively. Both the retailer and manufacturer pay backorder penalty cost for any quantity not fulfilled during a given period. In this study, instead of changing both inventory holding cost and backorder penalty cost at the same time, the inventory holding cost is held steady and only backorder penalty cost is changed. The backorder penalty cost for retailer is assumed 1.5 times the backorder penalty cost for manufacturer. Also to facilitate valid comparison, the inventory replenishment policy and the production policy remains the same for all three supply chain strategies.

The output data (i.e. retailer cost and manufacturer cost) from the three simulation models are analyzed to investigate cost benefits of CPFR and VMI over TSC. To make valid statistical inferences, it is important to reduce variance of the output data. To simulate and compare different system configurations, a variety of variance reduction techniques are discussed in Law and Kelton (2000), including the use of common random numbers (CRN). For this study, the same common random number sequence is used to generate same customer demand data for all three simulation models. In addition, sample size (number of replications) for a certain level of precision is determined using confidence interval method, as stated by Law and Kelton (2000), wherein the level of precision is differentiated as 'absolute precision' and 'relative precision'. The confidence interval (CI) is a measure of error and the confidence level (CL) is the level of significance $(\alpha)$. The confidence interval quantifies, confidence (probability) that the true (but unknown) mean falls within an interval, whose boundaries are calculated using the point estimates and the margin of error. It is important to remember that the variance of the output data can be reduced; however it cannot be totally eliminated, as the input data (customer demand) is a random variable. Based on a relative precision of 5 percent and confidence level of $95 \%$, a sample size of 60 replications is selected for this study.

Generally, stochastic processes for most real systems do not have a steady state distributions, since the parameters of the system may continue to change over time. In this research, the customer demand for the retailer varies from period to period, and therefore the steady state parameters are not well defined or do not exist. In this situation, typically there will be a fixed amount of data describing how input parameters can be varied over some time duration. This in effect provides a terminating event for simulation and thus analysis techniques for terminating simulations will be appropriate (Law and Kelton, 2000). To determine the performance measures for a terminating simulation, the initial conditions should be representative of the actual system. In this research, all three simulation models are run for a total of 1144 periods, with the first 104 periods used to initialize the system (warm up period), and the remaining 1040 periods (equal to 20 years) is then used for the analysis. Increasing the warm up period will not have a significant impact, as the output values from all three simulation models are relatively stable for different warm-up periods. Initial inventory of 300 units ( 3 times the average demand per period) is used for both the retailer and manufacturer at the start of the simulation run. To determine which control variables have a significant impact on cost benefits for both the retailer and the manufacturer in CPFR and VMI collaboration strategies, valid comparisons are made under different factor combinations. Some of the main results from this study are 
shown below. The statistical software 'Minitab $16^{\prime}$ is used for the analysis.

\section{RESULTS AND DISCUSSIONS}

The retailer cost and the manufacturer cost from all three simulation models are analyzed to investigate the inventory management cost benefits of CPFR and VMI over TSC. To investigate research question 1 , the average retailer cost and the average manufacturer cost based on output data for all factor combinations from the three simulation models is shown in Figure 4. It shows that on average, both CPFR and VMI perform better than TSC in reducing inventory

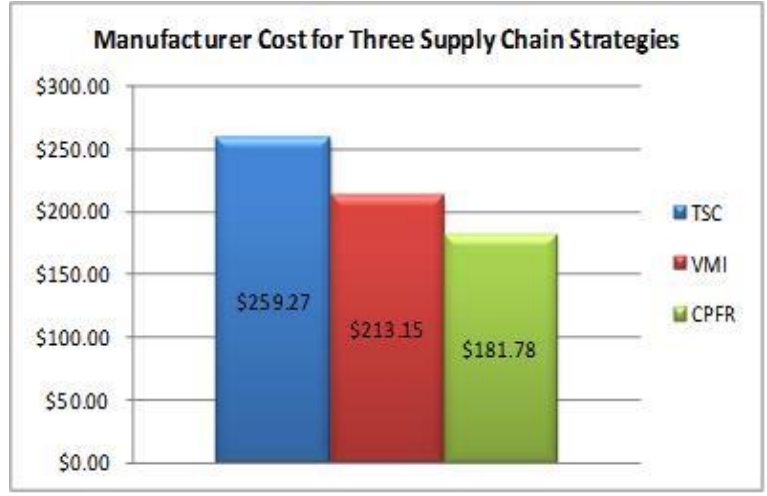

management cost for the retailer and the manufacturer. For the retailer on average, VMI reduces cost by $16.7 \%$ while CPFR reduces cost by $24.1 \%$ when compared to TSC. Similarly, for the manufacturer on average, VMI reduces cost by $17.8 \%$ while CPFR reduces cost by $29.9 \%$ compared to TSC. So based on the supply chain setting considered in this study, it is shown that on average, CPFR performs better than VMI in reducing inventory management cost for both the retailer and the manufacturer. Other studies in multi-echelon supply chains (Cigolini \& Rossi, 2006, Sari, 2008) have made similar conclusions that CPFR achieves higher cost reduction when compared to VMI and TSC.

Figure 4 - Average Cost in the Three Supply Chain Strategies

\subsection{Impact of Control Factors on Cost Benefits in CPFR and VMI Collaboration Strategies}

For comparing alternative system configurations, appropriate statistical methods are essential to avoid making incorrect conclusions. In this study, further analysis is performed using 'Pairwise Comparisons' method to determine the impact of production capacity, backorder penalty cost and delivery lead times on the cost of inventory management in a variable demand environment. Based on Law and Kelton (2000) for comparing alternative system configurations, 'Pairwise Comparisons' method is used to compare CPFR and VMI with TSC using a 95\% confidence level. Pairwise comparison method uses a paired-t confidence interval for difference between paired samples, and interpretation of any significant difference is based on whether the confidence interval misses or contains zero. If the confidence interval does not contain zero, then the two systems being compared are statistically significantly different. In this study, TSC is used as base line for comparison, and the results comparing CPFR with TSC and VMI with TSC in low variable demand and in high variable demand environment are shown below.

\subsection{Impact of Production Capacity (PCM) and Vari- able Demand (VDR)}

Production capacity of manufacturer can play a significant role in pursuing the appropriate collaboration strategy for both the manufacturer and the retailer. Manufacturer uses a lot-for-lot production strategy, so determining the optimal order quantity (by retailer) and optimal production quantity (by manufacturer) becomes important to minimize the inventory management cost. First, the average cost benefits of CPFR and VMI compared to TSC in low production capacity and in high production capacity environment is tabulated as shown in Figure 5. It is shown from Figure 5, both VMI and CPFR help in reducing retailer cost and manufacturer cost in low production capacity as well as in high production capacity environment. Also, it is shown that CPFR 
achieves higher cost reduction for the retailer and manufacturer in both low as well as in high production capacity environment.
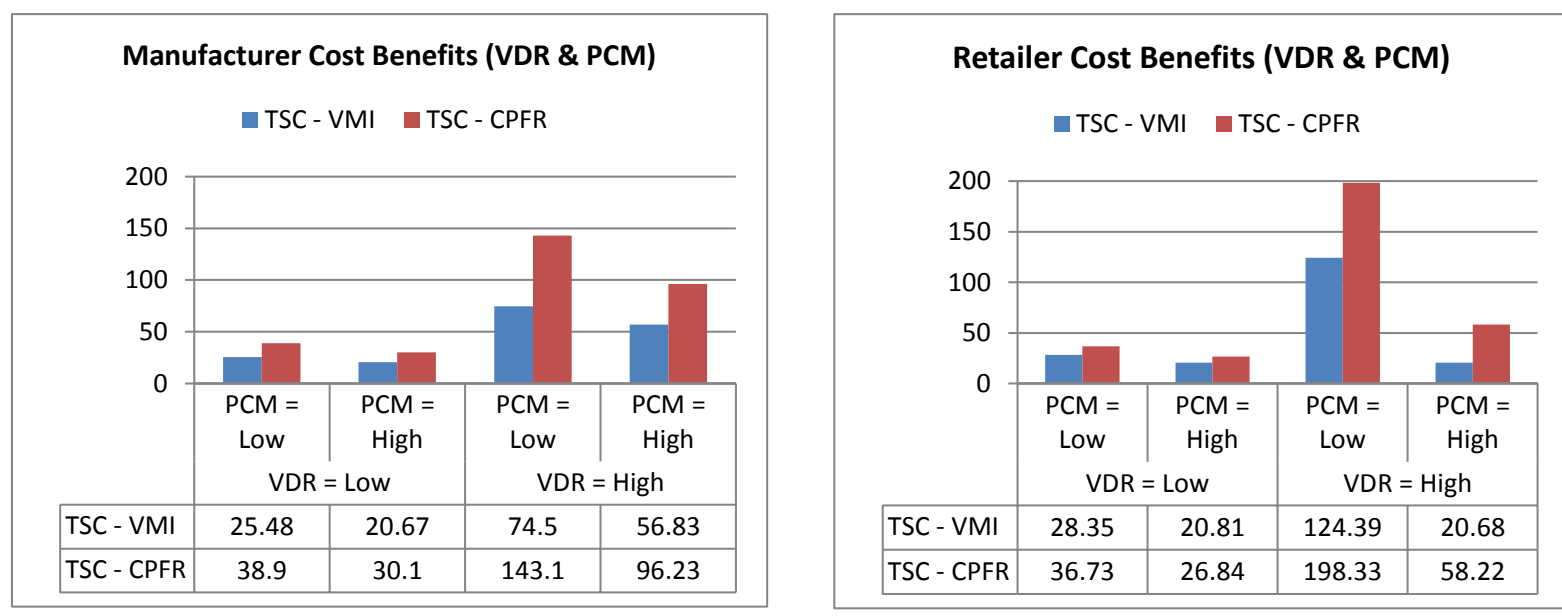

Figure 5 - Cost benefits of CPFR and VMI for different PCM and VDR

Next, to determine if these cost benefits are statistically significant, the confidence intervals comparing CPFR and VMI with TSC in low production and in high production capacity environment is tabulated as shown in Table 3. It is shown from Table 3, that when compared to TSC, there is a statistically significant difference in retailer cost and manufacturer cost for both CPFR and VMI supply chain strategies in low as well as in high production capacities.

Table 3 - Confidence Intervals for different PCM and VDR

\begin{tabular}{|c|c|c|c|c|}
\hline \multirow{2}{*}{$\begin{array}{c}\text { Manufacturer } \\
\text { Cost }\end{array}$} & \multicolumn{2}{|c|}{ VDR = Low } & \multicolumn{2}{c|}{ VDR = High } \\
\cline { 2 - 5 } & PCM = Low & PCM $=$ High & PCM = Low & PCM = High \\
\hline TSC - VMI & $(23.35,27.60)$ & $(19.07,22.25)$ & $(66.87,82.09)$ & $(52.48,61.19)$ \\
\hline TSC - CPFR & $(35.91,41.88)$ & $(27.86,32.31)$ & $(132.52,153.52)$ & $(89.50,102.97)$ \\
\hline
\end{tabular}

\begin{tabular}{|c|c|c|c|c|}
\hline \multirow{2}{*}{$\begin{array}{c}\text { Retailer } \\
\text { Cost }\end{array}$} & \multicolumn{2}{|c|}{ VDR $=$ Low } & \multicolumn{2}{c|}{ VDR = High } \\
\cline { 2 - 5 } & PCM = Low & PCM = High & PCM = Low & PCM = High \\
\hline TSC - VMI & $(25.14,31.56)$ & $(18.53,23.08)$ & $(108.26,140.53)$ & $(16.76,24.59)$ \\
\hline TSC - CPFR & $(32.68,40.78)$ & $(23.97,29.71)$ & $(176.62,219.45)$ & $(51.57,64.88)$ \\
\hline
\end{tabular}

It is shown that when production capacity is high, the cost benefits of CPFR and VMI are generally lower, especially when demand variability is low. However, when production capacity is low and the demand variability is high, significantly higher cost benefits can be achieved in CPFR strategy for both the retailer and the manufacturer. This suggests that when production capacity is low, it is more beneficial for both supply chain partners to pursue CPFR collaboration strategy and specially gain significantly higher cost benefits in high variable demand environment. 


\subsection{Impact of Backorder Cost (BOP) and Variable De- mand (VDR)}

In a variable demand environment, backorder penalty cost can have a significant impact in pursuing the appropriate collaboration strategy to reduce cost of inventory management for both the manufacturer and the retailer. The cost benefits of CPFR and VMI compared to TSC in low as well as in high backorder penalty costs and demand variability's are tabulated and shown in Figure 6. It is shown that both VMI and CPFR help in reducing the retailer cost and manufacturer cost under different backorder penalty costs. The cost benefits of CPFR and VMI increases, as demand variability and the backorder penalty cost increases. Also, higher cost benefits are achieved in CPFR strategy under all backorder penalty costs, both in low as well as in high variable demand environment.

Next, to determine if these cost benefits are statistically significant, the confidence intervals comparing CPFR and VMI with TSC in low backorder penalty cost and in high backorder penalty cost are tabulated as shown in Table 4. It is shown from Table 4, that when compared to TSC, there is a statistically significant difference in retailer cost and manufacturer cost for both CPFR and VMI supply chain strategies in low as well as in high backorder penalty costs.
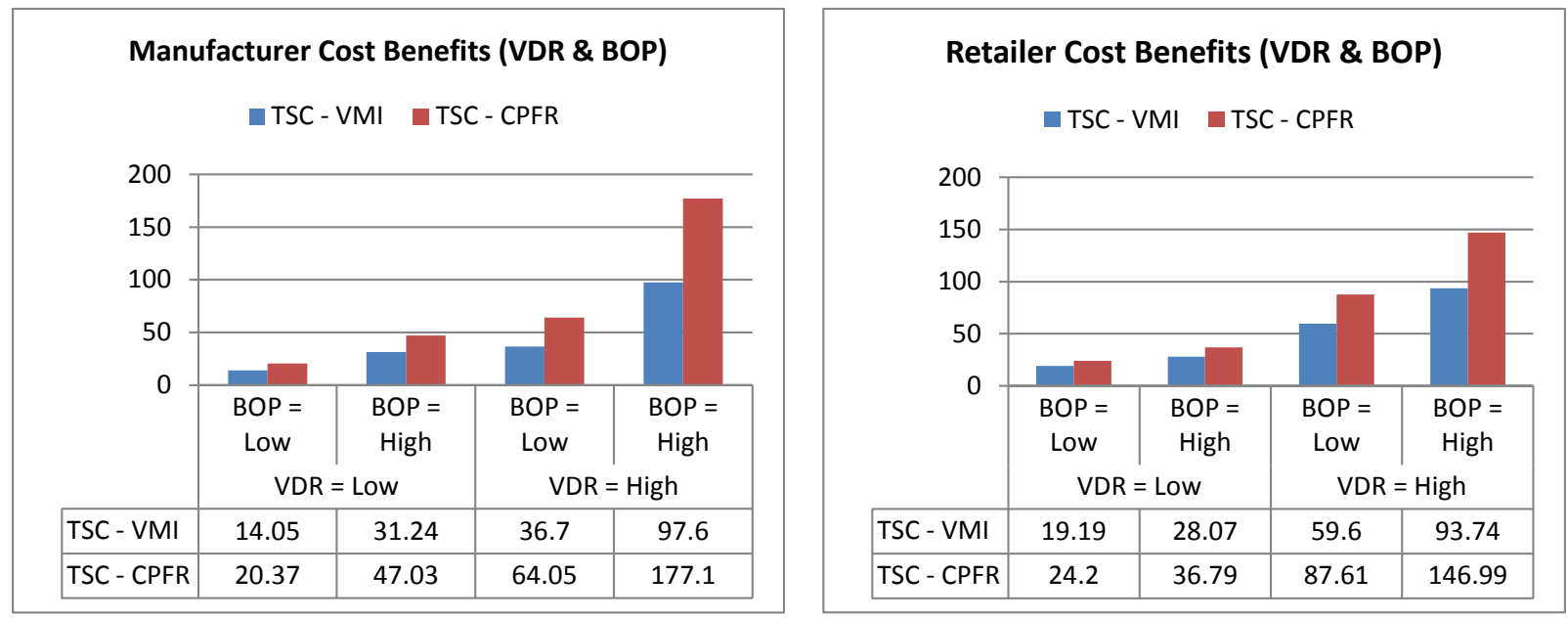

Figure 6 - Cost benefits of CPFR and VMI for different BOP and VDR

Table 4 - Confidence Intervals for different BOP and VDR

\begin{tabular}{|c|c|c|c|c|}
\hline \multirow{2}{*}{$\begin{array}{c}\text { Manufacturer } \\
\text { Cost }\end{array}$} & \multicolumn{2}{|c|}{ VDR $=$ Low } & \multicolumn{2}{c|}{ VDR $=$ High } \\
\cline { 2 - 5 } & BOP $=$ Low & BOP $=$ High & BOP = Low & BOP = High \\
\hline TSC - VMI & $(13.13,14.95)$ & $(28.95,33.51)$ & $(33.82,39.58)$ & $(90.14,104.99)$ \\
\hline TSC - CPFR & $(19.16,21.58)$ & $(43.84,50.21)$ & $(60.33,67.77)$ & $(166.77,187.38)$ \\
\hline
\end{tabular}

\begin{tabular}{|c|c|c|c|c|}
\hline \multirow{2}{*}{$\begin{array}{c}\text { Retailer } \\
\text { Cost }\end{array}$} & \multicolumn{2}{|c|}{ VDR $=$ Low } & \multicolumn{2}{c|}{ VDR = High } \\
\cline { 2 - 5 } & $\mathrm{BOP}=$ Low & BOP $=$ High & BOP $=$ Low & BOP = High \\
\hline TSC - VMI & $(17.16,21.19)$ & $(24.87,31.26)$ & $(51.49,67.69)$ & $(80.02,107.66)$ \\
\hline TSC - CPFR & $(21.70,26.68)$ & $(32.73,40.85)$ & $(76.88,98.32)$ & $(127.85,166.13)$ \\
\hline
\end{tabular}


When backorder penalty costs are high, higher cost benefits are achieved for both the manufacturer and the retailer. It is shown that when backorder penalty costs are high, information sharing in VMI and CPFR collaboration strategy has a significant benefit in reducing the cost of inventory management for both supply chain partners. In CPFR strategy, the availability of forecast, sales and inventory level information helps the manufacturer to improve their production planning and their service level to the retailer. This in turn reduces inventory management cost by reducing the backorder penalty cost for both the manufacturer and retailer. This suggests that there are significant cost benefits for both the manufacturer and retailer to pursue CPFR strategy in all backorder penalty cost situations, and specially gain higher cost benefits when demand variability and backorder penalty costs are high.

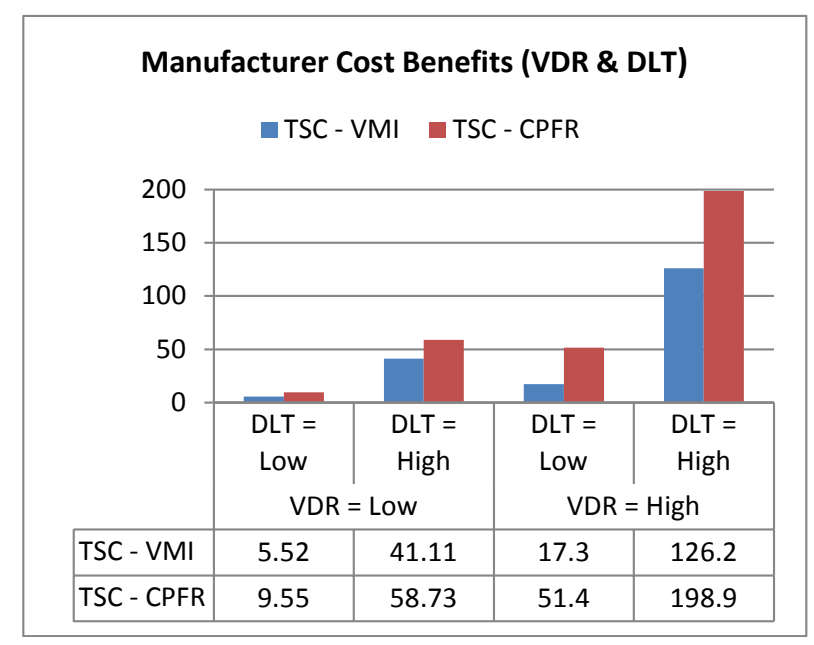

\subsection{Impact of Delivery Lead Time (DLT) and Vari- able Demand (VDR)}

In a variable demand environment, delivery lead time can have a significant impact on the inventory management cost for both the manufacturer and retailer. When delivery lead time is high (i.e. long), the cost of inventory usually increases, due to higher safety stock or higher backorder penalty costs. So pursuing appropriate collaboration strategy can help in reducing inventory management cost for both the manufacturer and the retailer. In a variable demand environment, the cost benefits of CPFR and VMI compared to TSC in low as well as in high delivery lead times are shown in Figure 7. Also, to determine if these cost benefits are statistically significant, the confidence intervals comparing CPFR and VMI with TSC in low as well as in high delivery lead times are tabulated as shown in Table 5.

Figure 7 - Cost benefits of CPFR and VMI for different DLT and VDR

As shown in Table 5, when delivery lead time is low (i.e. short) and demand variability is low, there is no significant difference in retailer cost between VMI and TSC and also has comparatively smaller cost benefits in CPFR strategy. Therefore there is less in-

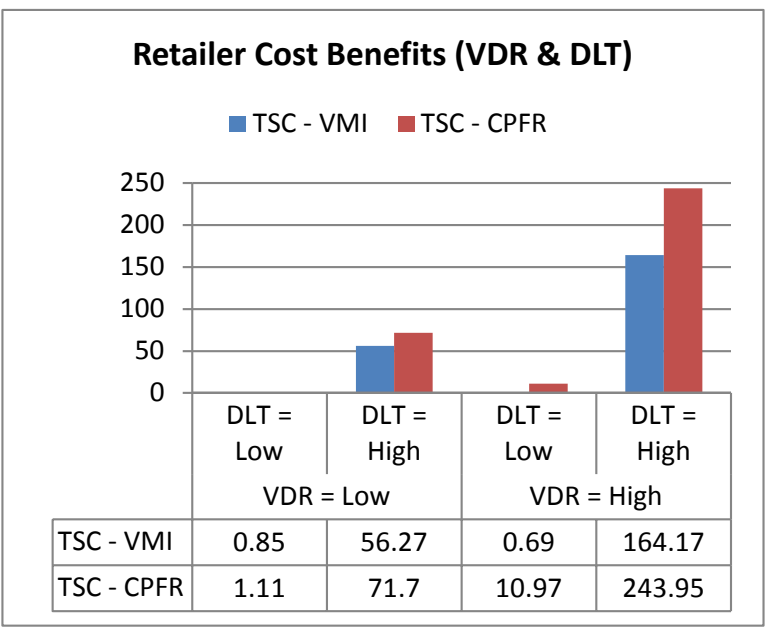

when for retailer to pursue VMI or CPFR strategy low. However, it is interesting to see that the cost benefits for manufacturer are still significant, especially in CPFR strategy. 


\section{Table 5 - Confidence Intervals for different DLT and VDR}

\begin{tabular}{|c|c|c|c|c|}
\hline \multirow{2}{*}{$\begin{array}{c}\text { Manufacturer } \\
\text { Cost }\end{array}$} & \multicolumn{2}{|c|}{ VDR $=$ Low } & \multicolumn{2}{c|}{ VDR $=$ High } \\
\cline { 2 - 5 } & DLT $=$ Low & DLT $=$ High & DLT $=$ Low & DLT $=$ High \\
\hline TSC - VMI & $(5.29,5.75)$ & $(39.49,42.71)$ & $(15.74,18.94)$ & $(120.35,132.12)$ \\
\hline TSC - CPFR & $(9.17,9.93)$ & $(56.39,61.05)$ & $(48.48,54.23)$ & $(189.77,208.10)$ \\
\hline
\end{tabular}

\begin{tabular}{|c|c|c|c|c|}
\hline \multirow{2}{*}{$\begin{array}{c}\text { Retailer } \\
\text { Cost }\end{array}$} & \multicolumn{2}{|c|}{ VDR $=$ Low } & \multicolumn{2}{c|}{ VDR $=$ High } \\
\cline { 2 - 5 } & DLT $=$ Low & DLT $=$ High & DLT $=$ Low & DLT $=$ High \\
\hline TSC - VMI & $(0.74,0.95)$ & $(54.44,58.09)$ & $(-2.11,1.55)$ & $(141.86,186.41)$ \\
\hline TSC - CPFR & $(0.98,1.25)$ & $(68.41,74.98)$ & $(8.43,12.08)$ & $(226.84,270.96)$ \\
\hline
\end{tabular}

When demand variability is high and delivery lead time is high, significantly higher cost benefits are achieved in CPFR strategy for both the retailer and manufacturer. It is well understood that when demand variability is high and no information is shared among supply chain members, there is increased variance (bullwhip effect) in order quantity for retailer and production quantity for manufacturer. In addition, when delivery lead time is high, increased variance in order quantity and production quantity will significantly increase the safety stock inventory or backorder penalty costs for both the manufacturer and retailer. In this situation, having forecast, sales and inventory level information available through CPFR strategy can minimize the variance to help improve service level and reduce inventory cost for both the manufacturer and retailer. This suggests that when delivery lead time is low, there is less incentive to pursue VMI or CPFR collaboration strategy, especially for the retailer. However, when delivery lead time is high, CPFR achieves significantly higher cost benefits for both the retailer and the manufacturer, especially in high variable demand environment.

\section{CONCLUSION}

This study uses discrete event simulation to investigate the cost benefits of CPFR and VMI collaboration strategies over TSC, to provide valuable managerial insight for both the manufacturer and retailer. The conceptual model used in this study is a two-echelon production-inventory system with a manufacturer and a retailer. Supply chain strategy, demand variability, production capacity, backorder penalty cost, and delivery lead time are used as con- trol variables. Manufacturer cost and retailer cost for inventory management are used as performance measures. Based on the supply chain setting considered in this research, it is shown that information sharing in VMI and CPFR does help in reducing inventory management cost for both the manufacturer and retailer. When compared to TSC, on average, VMI reduces cost by $17.8 \%$ while CPFR reduces cost by $29.9 \%$ for manufacturer. Similarly, on average, VMI reduces cost by $16.7 \%$ while CPFR reduces cost by $24.1 \%$ for retailer. It is shown that CPFR, which is considered the more advanced collaboration strategy, achieves higher cost benefits for both the retailer and the manufacturer. Other studies in multi-echelon supply chains (Cigolini \& Rossi, 2006, Sari, 2008) have made similar conclusions that CPFR achieves higher cost reduction than VMI for the supply chain. All factors considered in this study have a significant impact on cost of inventory management for both the manufacturer and retailer. CPFR achieves the highest cost benefits when demand variability is high, production capacity is low, backorder penalty cost is high and delivery lead time is long. When production capacity is high and delivery lead time is short, the cost benefits of VMI and CPFR are significantly lower.

\subsection{Recommendations for Future Research}

Although valuable insights can be gained from this research study to help the retailer and manufacturer to pursue appropriate collaboration strategy to reduce inventory management costs, however it is recognized that the conclusions provided here is limited to the supply chain setting considered in this study. In this research, a single retailer and 
a single manufacturer develop collaborative relationships with no incentive or conflicts with other supply chain partners. Periodic review order-up-to level policy is used to determine order quantity for retailer and production quantity for manufacturer during each period. Fixed production lead time for manufacturer and fixed delivery lead time to retailer are considered in this study. Also, only one set of inventory holding costs are considered for both the manufacturer and the retailer. So there are many opportunities to evaluate and strengthen these insights by investigating more parameters and developing a more realistic supply chain simulation model for VMI and CPFR collaboration strategies. Future studies can investigate the impact on manufacturer cost and retailer cost by considering other inventory management policies like $(\mathrm{s}, \mathrm{S})$ and $(\mathrm{R}$, Q) policies. Also, stochastic production lead times and stochastic delivery lead times can be used to expand this research study. In addition, it would be valuable to extend this study to investigate how different sets of inventory holding costs will have an impact on cost benefits achieved in VMI and CPFR collaboration strategies. Another area of future research to consider is the cost of information sharing for supply chain partners. Generally, information sharing in collaboration strategies is not free, as there are implementation and operational costs involved for both supply chain partners. So this research can be further extended to include implementation and operational costs to determine cost benefits of VMI and CPFR strategies for both the manufacturer and the retailer.

\section{REFERENCES}

Axsater, S., \& Rosling, K. (1993). Installation vs. Echelon Stock Policies for Multilevel Inventory Control. Management Science, Vol. 39, No 10, Pg. 1274-1280.

Baljko, J. (2003). VMI study shows cost disparity among partners. Electronic Buyer's News, April 7.

Boone, T., Ganeshan, R., \& Stenger, A. (2002). The benefits of information sharing in a supply chain. An exploratory simulation study. Netherlands: Kluwer Academic Publishers.

Bourland, K., Powell, S., \& Pyke, D. (1996). Exploiting timely demand information to reduce inventories. European Journal of Operational Research, 92, 239-253.

Chen, F., \& Zheng, Y. (1994). Echelon Stock (R, nQ) Policies in Serial Production Inventory Systems with Stochastic Demand. Management Science, Vol. 40, No. 10, Pg. 1262-1275.

Cigolini, S., \& Rossi, T. (2006). A note on supply risk and inventory outsourcing. Production Planning \& Control, 17(4), 424-437.
Cooke, J. (1998). VMI: Very mixed impact. Logistics Management and Distribution Report, 37(12), 51-53.

Disney, S., Naim, M., \& Potter, A. (2004). Assessing the impact of e-business on supply chain dynamics. International Journal of Production Economics, 89 (2), 109-118.

Esper, T., \& Williams, L. (2003). The value of collaborative transportation management (CTM): Its relationship to CPFR and information technology. Transportation Journal, 42 (4), 55-65.

Gavirneni, S., Kapuscinski, R., \& Tayur, S. (1999). Value of information in capacitated supply chains. Management Science, 45 (1), 16-24.

Hall, D., \& Saygin, C. (2011). Impact of information sharing on supply chain performance. International Journal of Advanced Manufacturing Technology, 10 (2)

Lapide, L. (2001). New developments in business forecasting. Journal of Business Forecasting Methods E Systems, 20 (4), 11-13.

Lau, J., Huang, G., \& Mak, K. (2004). Impact of information sharing on inventory replenishment in divergent supply chains. International Journal of Production Research, 42 (5), 919-941.

Law, A., \& Kelton, W. (2000). Simulation modeling and analysis. McGraw Hill, Third Edition.

Lee, H., Padmanabhan, V., \& Whang, S. (1997). The bullwhip effect in supply chains. Sloan Management Review, 38 (3), 93-102.

Lee, H., So, K., \& Tang, C. (2000). The value of information sharing in a two level supply chain. Management Science, 46 (5), 626-643.

Lewis, T. (1998). Electronic Warehouses. Datamation, Vol. 44 No. $1,17-18$

Sari, K. (2008). On the benefits of CPFR and VMI: A comparative simulation study. International Journal of Production Economics, $113,575-586$.

Seifert, D. (2003). Collaborative Planning, Forecasting and Replenishment. How to create a supply chain advantage. AMACOM Div. American Management Association.

Setamanit, S. (2009). Exploring the effect of Vendor Managed Inventory on supply chain partner using simulation. PICMET 2009 Proceedings, August 2-6

Simchi-Levi, D., \& Zhao, Y. (2003). The value of information sharing in a two stage supply chain with production capacity constraints. Naval Research Logistics, 50(8), 888-916.

Wilson, R. (2006). 17th Annual Logistics Report. Lombard, IL: Council of Supply Chain Management Professionals.

Xu, K., Dong, Y., \& Evers, P. (2001). Towards better coordination of the supply chain. Transportation Research, 37, 35-54.

Zhao, Y. (2002). The value of information sharing in a two stage supply chain with production capacity constraints: The infinite horizon case. Manufacturing \& Service Operations Management, 4(1), 21-24. 
Raj Kamalapur is an Assistant Professor in the College of Business at the University of Wisconsin Oshkosh. He received his PhD in Industrial Engineering from Western Michigan University in December 2011. His research interests are in the area of inventory management, and supply chain collaboration, specifically VMI and CPFR. He has published in American Journal of Industrial and Business Management and has presented at many DSI conferences.

David Lyth is a Professor in the College of Engineering and Applied Sciences at Western Michigan University. He received his Ph.D. in Production/Operations Management from Michigan State University. His research interests are in service quality, empathic design and innovation, and healthcare engineering. He has published widely in journals such as Engineering Management Journal, Managing Service Quality, International Journal of Quality and Reliability Management and others.

Azim Houshyar is a Professor in the College of Engineering and Applied Sciences at Western Michigan University. He received his PhD in Industrial and Systems Engineering from University of Florida. His research interests are in operations research, reliability and simulation of manufacturing processes. He has widely published in journals such as International Journal of Modeling and Simulation, Journal of Manufacturing Systems and others. 